\title{
PROBLEMS IN THE ECONOMIC THEORY OF INSURANCE
}

\author{
KARL BORCH
}

\section{INTRODUCTION}

I.I More than ten years ago I wrote a paper with the title "The Economic Theory of Insurance" [6]. I was not particularly happy about this paper, and I do not think it contributed much to the development of a sastifactory theory. The paper did however make me-and I hope some readers-acutely aware of the difficulties and problems which must be overcome before a proper theory can be constructed. These problems are still unsolved, so I have on the present occassion chosen a more modest title for a paper on substantially the same subject.

I.2. Insurance is an economic activity of some importance, and there is an obvious need for a theory to explain and analyse the activity in the insurance sector of the economy. During the last decade many economists seem to have felt the need, and to have taken it as a challenge. The results have been a fair amount of research, and a number of publications, which I shall not try to review here. It may however be useful to refer to three very recent survey articles by Farny [Io], Ferry [II] and Rosa [I4], which give extensive bibliographies. The three articles seem to indicate that the economics of insurance is becoming a fashionable subject of research.

\section{A Few Historical Notes}

2.I. Most economists have realised that insurance is important and interesting, even if they were unable to develop an adequate theory for this particular economic activity. The classical paper by Bernoulli [3] contains several references to insurance problems, and Adam Smith's [15] remarks about insurance are often quoted. He observed that the profit of insurance companies was modest, compared to the profits made by organizing lotteries. This observation implies that the inclination to gamble in some way must be stronger than the risk aversion in the economy as a whole.

2.2. An early attempt at a systematic analysis of the problems which are central in insurance is found in Böhm-Bawerk's first book [4], actually his thesis, or "Habilitationsschrift". In this book he considers what we today would call "conditional claims". 
If your property is stolen, you have the right to recover it, if the police should catch the thief. Böhm-Bawerk studied the value one should attach to such rights. It is curious that it never seemed to occur to him that insurance companies, as a matter of routine, would have to evaluate such rights. If he had seen the connection, Böhm-Bawerk might well have become the first student of the IBNR-problem.

2.3. There were other Austrians who were intrigned by the problems in economic theory which were suggested by insurance. In a paper presented to the 6th International Congress of Actuaries in Vienna, Tauber [I6] suggested that reinsurance premiums should be determined as equilibrium prices in a market where conditional claims (Ansprüche) were bought and sold. Beyond presenting this idea, he did not contribute much to the development of an economic theory of insurance, apparently because he, like many actuaries of his generation, became too fascinated by his own mathematical manipulations.

A more remarkable contribution was made by another Austrian Lindenbaum [I2], who argued that the theory of insurance must be based on the "supply of security" (Sicherheitsangebot) and the "demand for risk" (Risikennachfrage). The paper was however published in 1932, and we may assume that economists in the following years were preoccupied with other problems. In any case, nobody seems to have followed up the ideas of Lindenbaum, and his paper is virtually forgotten.

2.4. In America an attempt at developing a complete theory of insurance was made by Willett [I7] at the beginning of this century. His book is in many ways remarkable, but it seems somehow out of touch with the contemporary economic theory, and this may be why it has not inspired other economists to continue Willett's research. The same remarks can be applied to the book by Pfeffer [I3], published 55 years later, which also seems to have had little influence on research in the two following decades.

It is probably fair to say that the present interest in the economics of insurance springs from the theory of the economics of uncertainty which has been developed during the last twenty years. The pioneering work in this field is certainly Arrow's paper from 1952 [2]. This short elegant paper does really contain an economic theory of insurance as a special case. In the following sections we shall do little more than discussing this special case in some detail. 


\section{Insurance and Market Equilibrium}

3.I. It is convenient to begin this section with a brief restatement of the classical theory of markets of pure exchange.

We consider a market of $m$ persons and $n$ goods. In the initial situation person $i$ holds an amount $x_{i j}$ of good $j$. Hence the initial allocation is described by a matrix $\left\{x_{i j}\right\}$. The persons exchange goods among themselves, and arrive at a final allocation described by the matrix $\left\{y_{i j}\right\}$.

If goods are neither produced nor destroyed during the exchanges, the following "conservation" condition must be satisfied

$$
\sum_{i=1}^{m} x_{i j}=\sum_{i=1}^{m} y_{i j} \quad \text { for } j=\mathbf{I}, 2, \ldots, n \text {. }
$$

It is usually assumed that all exchanges have to take place at market prices, so that the market value of a person's holdings of goods does not change during the transactions. This assumption gives the condition

$$
\sum_{i=1}^{n} p_{j} x_{i j}=\sum_{i=1}^{n} p_{j} y_{i j} \quad \text { for } i=\mathrm{I}, 2, \ldots, m
$$

where $p_{j}$ is the price of good $j$.

The behavioral assumption leading to condition (2) is of course very restrictive. It rules out free bargaining and negotiations over the exchange of goods.

Further it is usual to assume that the preferences of person $i$ can be represented by a utility function

$$
u_{i}\left(y_{i 1}, \ldots, y_{i n}\right)=u_{i}\left(y_{i}\right) \quad i=\mathrm{I}, 2, \ldots, m .
$$

This assumption is not completely trivial. It implies complete selfishness, in the sense that a person will only consider "his own row" when he evaluates an allocation matrix.

3.2. With these assumptions, person $i$ will maximize (3) subject to condition (2)-his "budget equation". This problem can be solved for any $n$-tuple of prices. The conditions (r) must however also be satisfied, and this will make it possible to determine the prices. Hence under reasonable assumptions about the shape of the utility functions, we obtain a solution, consisting of a final allocation $\left\{y_{i j}\right\}$, and an $n$-tuple of equilibrium prices. This solution is usually called "competitive equilibrium". The final allocation in 
this solution is Pareto optimal, i.e. there exists no other allocation $\left\{\bar{y}_{i j}\right\}$ such that

$$
u_{i}\left(\bar{y}_{i}\right) \geq u_{i}\left(y_{i}\right)
$$

with at least one strict inequality.

It is easy to see that the set of Pareto optimal allocations can be found by maximizing

$$
\sum_{i-1}^{m} k_{i} u_{i}\left(y_{i}\right)
$$

subject to condition (I). Here $k_{1}, \ldots, k_{m}$ are arbitrary positive constants. Since the maximand (4) is homogeneous in the $k$ 's, it follows that the set of Pareto optimal allocations is a manifold of $m$-I dimensions.

We get a single element in this set if we impose the behavioral assumptions behind the conditions (2), i.e. if we assume that all exchanges have to take place at equilibrium prices, and that each person has to satisfy his budget equation.

3.3. If we want to adapt this model to insurance, it is natural to assume that in the initial situation person $i$ is exposed to a risk which can cause him a loss, represented by a stochastic variable $x_{i}$, with the distribution $F_{i}(x)$. It is natural to assume that $F_{i}\left(x_{i}\right)$ is the marginal distribution of a joint probability distribution $F\left(x_{1}, \ldots, x_{m}\right)$.

If the attitude to risk of person $i$ is represented by the utility function $u_{i}(x)$, his expected utility in the initial situation will be

$$
\int_{0}^{\infty} u_{i}(-x) d F_{i}(x)
$$

In some cases it is convenient to replace this expression with

$$
\int_{0}^{\infty} u_{i}\left(S_{i}-x\right) d F_{i}(x)
$$

where $S_{i}$ is interpreted as the "initial wealth" of person $i$.

In the model we have outlined, we can assume that the $m$ persons exchange risks among themselves. There is however no natural units of risk, to which prices can be assigned, so it seems a little artificial to analyse the situation as a classical market of pure exchange. 
3.4. It seems more natural to assume that the $m$ persons in some way will negotiate their way to some risk-sharing arrangement. A general arrangement of this kind is defined by $m$ functions

$$
y_{i}\left(x_{1}+, \ldots+x_{m}\right)=y_{i}(x) \quad i=\mathrm{I}, 2, \ldots, m
$$

where $y_{i}(x)$ is the amount to be contributed by person $i$, if the sum of individual losses is $x$. Since the model is closed so that all losses have to be born by the group of $m$ persons, we must have

$$
\sum_{i=1}^{m} y_{i}(x)=\sum_{i=1}^{m} x_{i}=x .
$$

It can be shown [5] that the set of Pareto optimal risk-sharing arrangements is given by the $m$-tuple of functions $y_{i}(x)$ which satisfy the condition (5) and

$$
u_{i}^{\prime}\left(y_{i}(x)\right)=k_{i} u_{1}^{\prime}\left(y_{1}(x)\right) \quad i=\mathrm{I}, 2, \ldots, m .
$$

Here $k_{1}=\mathrm{I}$, and $k_{2}, \ldots, k_{m}$ are arbitrary positive constants. This result is valid only if all utility functions are increasing and concave, i.e. if $u_{i}^{\prime}()>$. and $u_{i}^{\prime \prime}()<$.0 .

3.5. The $y$-functions which represent Pareto optimal arrangements will usually have a complicated form. It can be shown [7] that they will be linear, i.e.

$$
y_{i}(x)=a_{i} x+b_{i}
$$

only if the utility functions of all persons belong to one of the following three classes

(i) $u_{i}(x)=\left(x-c_{i}\right)^{\alpha}$

(ii) $u_{i}(x)=\log \left(x-c_{i}\right)$

(iii) $u_{i}(x)=\mathrm{r}-e^{-\alpha_{i} x}$.

Positive linear transformations of these functions will of course give the same results, since $u(x)$ and $w(x)=A u(x)+B$, with $A>0$ represent the same preference ordering over any set of probability distributions.

Any of these three classes seems too narrow to give room for the different individual attitudes to risk which one would expect to find in the real world. The classes (i) and (ii) imply that all persons have the same basic attitude to risk. Differences in preferences are such that they can be explained by differences in "initial wealth". Class (iii) gives room for differences in risk aversion, but implies that preferences are independent of initial wealth. 
3.6. In practice it does not often happen that a group of people negotiate a scheme for sharing risks, i.e. create their own insurance arrangement. The institutions in the real world which come closest to our model, may be the P \& I clubs, which can be seen as rather exclusive mutual insurance companies, created by ship owners. The risk sharing in most $\mathrm{P} \& \mathrm{I}$ clubs is virtually linear, and this may for all practical purposes be a Pareto optimal arrangement. It is not unreasonable to assume that members of the club have similar preferences, and that these preferences can be represented approximately by utility functions in one of the three classes in the preceding paragraph.

Most persons who want to participate in a risk-sharing arrangement will have to go to an insurance company. Usually the company will offer a fair, but limited choice of standard insurance contracts, and people choose according to their preferences. In this way a risk-sharing arrangement is created between customers of the company, and if the company has share holders, they will also participate in the arrangement. Through exchange of reinsurance between companies, the arrangement can be extended until it becomes virtually universal. It seems however unlikely that a risk-sharing arrangement built up in this way should satisfy conditions (5) and (6) in para 3.4 and be Pareto optimal.

3.7. These considerations lead us to our main point. Economic theory gives us some information about the form of optimal risksharing arrangements in an idealized world represented by our model. The practical question is then if it is possible to get reasonably close to an optimum through the existing framework of insurance institutions. If the risk-sharing arrangements which we observe in the real world seem far from any optimum, we should examine if this necessarily must be so. If the answer is in the negative, we should study the possibility of reaching better arrangements through institutional changes, or changes in insurance practice.

I do not propose to answer such far-reaching questions in this paper. Instead we shall examine some of the assumptions behind the theoretical results derived in the preceding paragraphs.

\section{Insurance and the Assumptions in Economic Theory}

4.I. In the classical market model it is fairly safe to assume that a person has a preference ordering over collections of goods, and that this ordering can be represented by a utility function. When un- 
certainty is introduced, it may be slightly more risky to assume that a person has a consistent preference ordering over a set of probability distributions. If we make this assumption, the existence of a utility function follows, and the objective of the person will be to maximize expected utility. It is, however, easy to construct simple examples which throw doubt upon this assumption.

4.2. Consider a person with an initial wealth $S$, which includes an asset worth $A$, which can be lost with a probability $p$. Assume that he can obtain insurance against the loss of the asset in the following form: If he pays a premium $k P$ to an insurance company, he will receive a compensation $k A$ if the asset is lost. His problem is then to determine the optimal value of $k$.

For an arbitrary value of $k$, the expected utility is

$$
U(k)=(\mathrm{I}-p) u(S-k P)+p u(S-k P-A+k A) .
$$

The first derivative is

$$
\begin{array}{r}
U^{\prime}(k)=-(\mathrm{I}-p) P u^{\prime}(S-k P)+p(A-P) u^{\prime}(S-k P- \\
-A+k A)
\end{array}
$$

and we find

$$
U^{\prime}(\mathrm{I})=\{p A-P\} u^{\prime}(S-P) .
$$

If $P=p A$, i.e. if the premium is equal to the expected compensation, we have $U^{\prime}(\mathrm{I})=0$. Normally the premium is loaded, so that we have $P>p A$, and $U^{\prime}(\mathrm{I})<0$.

It is easy to show that $U^{\prime \prime}(k)<0$, provided that $u^{\prime \prime}(x)<0$, i.e. if the person has risk aversion. Hence, if the premium is loaded, the person will not find it optimal to take full insurance cover.

4.3. The conclusion we have reached above seems to be contradicted by observations. A person may decide not to insure some of his assets. If however he decides to take insurance, he will usually insure the asset for its full value. We would be surprised if we observed that a person deliberately insured his house, car or baggage for, say $60 \%$ of its value.

Such observations from "household" insurance may not be conclusive. The consumer does not always behave as rationally as assumed in economic theory. "Impulse buying" is a well known concept in the theory of marketing, even if it has no place in the model which was outlined in Section 3. It seems however that we can observe the same effect in corporations where we must assume that insurance decisions are made after careful considerations. 
Fire insurance on industrial plant is usually written for the full value.

In ocean hull and hull interest insurance we may find arrangements which seem to imply a deliberate under-insurance, and hence may be consistent with the theoretical results we have derived. These cases are however difficult to judge, since the market value of a ship may bear little relation to the loss which the owner will suffer if the ship is lost.

4.4. In the example above we assumed proportionality between premium and compensation. This may be realistic, but it is clearly an unnecessary restriction on the choice offered to the customer. As a more general example consider a person exposed to a risk represented by the probability distribution $F(x)$, and assume that he by paying an insurance premium $P(y)$, will be entitled to a compensation $y(x)$, if the loss amounts to $x$.

We shall further assume that

$$
P(y)=(\mathrm{I}+\lambda) \int_{0}^{\infty} y(x) d F(x) .
$$

This means that the premium is proportional to the expected compensation, with $\lambda$ as the loading factor.

Let $S$ stand for the initial wealth of the person considered. For a given functional $P(y)$, his problem is then to determine the function $y(x)$ which maximizes the expected utility

$$
\int_{0}^{\infty} u(S-P(y)-x+y(x)) d F(x) \text {. }
$$

This problem was first formulated by Arrow [I], who showed that the solution is of the following form

$$
\begin{array}{ll}
y(x)=0 & \text { for } x<D \\
y(x)=x-\mathrm{D} & \text { for } x>D .
\end{array}
$$

Under this contract the insured will carry all losses smaller than the deductible $D$, and all excesses will be completely covered by the insurance company.

4.5. Arrow's result appears as a special case of the Pareto optimal risk-sharing arrangements presented in para 3.4 , if the insurance company is risk neutral. If the customer has preferences represented by the usual concave utility function $u_{1}(x)$, and if the company's utility function is linear, i.e. $u_{2}(x)=a x+b$, the optimal risk-sharing arrangement is given by the functions 


$$
y_{1}(x)=x \quad \text { and } \quad y_{2}(x)=0 \quad \text { for } x<D
$$

and

$$
y_{1}(x)=D \quad \text { and } \quad y_{2}(x)=x-D \quad \text { for } x>D .
$$

This result should have considerable interest. It shows that a simple and frequently used insurance contract can bring about a Pareto optimal arrangement. Before jumping to conclusions we should however scrutinize the two assumptions which led to this result.

(i) Firstly the arrangement will be illusory if the company should be unable to fulfill its obligations under the contract. Hence the result is valid only if the supervision is so strict that the probability of ruin is negligible.

(ii) Secondly we assumed that the insurance company was risk-neutral. This cannot be correct if the company is a cedent in the reinsurance market. Hence the result can be valid only for relatively small risks, of the type that the company does not reinsure.

It seems that these two conditions often will be satisfied in the real world, and this immediately leads to a practical question. Why do not insurance companies offer a larger choice of deductibles in the insurance contracts sold to the ordinary households? For most kinds of simple property insurance there should be no serious technical difficulties involved. The rating system would however become more complicated, and this would probably make the whole risk-sharing arrangement more expensive to operate.

4.6. In most situations covered by liability insurance, there is theoretically no limit to the loss which the prospective insurance buyer can suffer. In such cases the insurance contract will however usually be drawn up so that the company's liability is limited. A similar procedure is used for many insurance contracts covering medical expenses.

This kind of insurance is not very satisfactory to the customer. It leads to the complaint that the insurance is not effective when it is most needed.

If a company is reluctant about accepting unlimited liabilityagainst a premium with proportional loading-the company evidently has a positive risk aversion. This was explicitly assumed away in the preceding paragraph, so the argument based on Pareto optimality does no longer apply. It seems however that in many cases it should be possible to devise contracts with unlimited 
liability and non-proportional loading which would bring about a risk-sharing arrangement closer to an optimum than the existing methods can do.

\section{Final Remarks}

5.I. In economic theory the model of a pure exchange market is generalized by bringing in production. The new elements in the generalized model are:

(i) An initial endowment of input factors, described by a matrix $\left\{w_{i h}\right\}$. The interpretation is that person $i$ owns an amount $w_{i h}$ of input factor $h$. The input factors may be labour or raw materials.

(ii) An $n$-tuple of production facilities, described by production functions

$$
x_{j}=f_{j}\left(w_{1}, w_{2}, \ldots\right) \quad j=\mathbf{I}, 2, \ldots, n,
$$

which define how input factors can be transformed into consumer goods.

It is usually assumed that each production facility is operated so that its profit is maximized.

Each person will then sell a part, or all of his endowment to the production facilities. He will use the proceeds, and any profits he may receive from the production facilities, to buy consumer goods.

5.2. The model we have outlined leads to a problem which can be solved. The solution will consist of: Equilibrium prices for all input factors and consumer goods, and of a matrix $\left\{x_{i j}\right\}$ describing the final allocation of consumer goods.

Elements of this model can certainly be applied to insurance, and the possibilities have been explored by a number of authors, i.a. Eisen [8] and Farny [9], and they have obtained a number of potentially useful results.

It seems however, to me at least, that insurance is essentially an exchange of risks, and that it is artificial to apply the theory of production to the design of contracts for such exchanges. Nevertheless the approach may prove fruitful. Administrative costs are high in many insurance companies, and it is important to find contract forms which are inexpensive to issue, control and fulfill. This means of course that managers of insurance companies, as managers in industry, always will have to look for ways of reducing production costs. 


\section{REFERENCES}

[I] Akrow, K,, (1974), "Optimal Insurance and Generalized Deductibles", Scandinavian Actuarial Journal, pp. I-42.

[2] Arrow, K.; ( (953), "I.e rôle de valeurs boursières pour la répartition la meilleure des risques", Colloques Internationaux du CNRS, XI, pp. 4I-48. English translation in Review of Economic Studies, I964, pp. $9 \mathrm{I}-96$.

[3] Bernoulli, D.; ( (1954), "Specimen Theoriae Novae de Mensura Sortis", St. Petersburg I738. English translation in Econometrica, pp. 23-46.

[4] Böнm-Bawerk, E.; (I 88I), "Rechte und Verhältnisse vom Standpunkte der Volkswirtschaftlichen Güterlehre", Innsbruck.

[5] BоксH, K., (I960), "The Safety Loading of Reinsurance Premiums", Skandinarisk Aktuarietidskrift, pp. I63-I84.

[6] Borch, K., (1967), "The Economic Theory of Insurance", The ASTIN Bulletin, Vol. IV pp. 252-264.

[7] Borch, K., (1968), "Economic Equilibrium under Uncertainty", International Economic Review, pp. 339-347.

[8] Eisen, R., (I97 I), "Zur Produktionsfunktion der Versicherung", Zeitschrift für die Gesamte Versicherungswissenschaft, pp. 407-419.

[9! Farny, D., (1965), Produktions- und Kostentheorie der Versicherung, Karlsruhe.

[10] FARNy, D., (1977), "Ansätze einer betriebswirtschaftlichen Theorie des Versicherungsunternehmens", The Geneva Papers on Risk and Insurance, No. 5, February, pp. 9-2I.

[I I] FerRy, C., (I977), "L'Approche Empirique de la Demande d'AssuranceVie", The Geneva Papers on Risk and Insurance, No. 5, February, pp. 22-34.

[12] Lindenbaum, J., (1932), “Ein Vierteljahrhundert der Bedarfstheorie der Versicherung", Zeitschrift für Nationalökonomie, pp. 75-99.

[13] Pfeffer, I., (1956), Insurance and Economic Theory, Richard Irwin.

[14] Rosa, J. J., (I977), "La Demande d'Assurance Non-Vie", The Geneva Papers on Risk and Insurance, No. 5, February, pp. 35-42.

[15] Smith, A., (1776), The Wealth of Nations, Edinburgh.

[16] Tauber, A., (r909), "Uber Risiko und Sicherheitszuschlag", Transactions of the Sixth International Congress of Actuaries, Vol. I, pp.78r-842.

[17] Willetr, A., (I901), The Economic Theory of Risk and Insurance, Columbia I'niversity Press. 